Original Research Paper

\title{
Organizational Culture from an Internal and External Stakeholders' Perspective
}

\author{
Ronald Jungnitsch, Jol Stoffers and Petra Neessen \\ Research Centre of Employability, \\ Zuyd University of Applied Sciences, Heerlen-Maastricht-Sittard, The Netherlands
}

\author{
Article history \\ Received: 10-04-2016 \\ Revised: $20-06-2016$ \\ Accepted: 21-06-2016 \\ Corresponding Author: \\ Jol Stoffers PhD \\ Research Centre of \\ Employability, Zuyd University \\ of Applied Sciences, \\ Heerlen-Maastricht-Sittard, \\ The Netherlands \\ Email: jol.stoffers@zuyd.nl
}

\begin{abstract}
A culture change within an organization may be of importance in this turbulent world. An assessment of the current and desired cultural profiles can help estimate as to whether any changes are required. In this study the organizational culture of a housing association was examined from both the staff's and external stakeholders' perspectives. How does the current culture compare with the desired culture? Do the external stakeholders perceive the organization's culture in a similar way? Do the staff's and external stakeholders' perceptions coincide with the organization's intended image? The results demonstrate that the external stakeholders' perceptions of the organizational culture in this case study are similar to those of the organization's staff. The organization's strategy, however, does not correspond to the perceived organizational culture.
\end{abstract}

\section{Keywords: Organizational Culture, OCAI, External Stakeholders}

\section{Introduction}

Over the course of time, organizations develop cornerstones to help them stand firm: Convictions that form each organization's specific identity and determine the way they operate. These cornerstones are also referred to as 'organizational culture'. The organizational culture is a valuable resource (Cadden et al., 2013). Organizations often deal with troublesome issues and housing associations are also no stranger to these. The tasks of the housing association vary from providing affordable and safe housing to providing innovative and market oriented housing. The housing association deals with issues such as population decline, ageing and hazing. The demands of the market and the demands of the government need to be taken into consideration and the activities of the housing association are highly subject to changes, therefore adapting to the needs of the market becomes more important. Dreimuller (2008) describes the increasing criticism of housing associations. The criticism boils down to the associations being insufficiently able to go with the times, whereas society is exerting increasing pressure to change that (Aslander and Witteveen, 2015). This would call for a radical change. Old habits in reasoning and practices must be abandoned. The cornerstone must be released, which is difficult. People are the culture and they would rather preserve than to change (Lines et al., 2015), but the developments continue and a standstill can be an organization's ruin.

This case study examined the organizational culture of a housing association. Both the current and the desired organizational culture were assessed. Research into organizational culture usually focuses on the current and desired culture from the perspective of the workers. It is, however, also important to investigate as to whether the current and desired culture are also in line with the external stakeholder's views (Aarons et al., 2014). Additionally, the desired and current culture were analyzed against the customer value strategies that the organization had determined.

\section{Organizational Culture}

Underlying the term organizational culture are two principles (Cameron and Quinn, 2011): an anthropological and a sociological one. Each of these principles considers the concept from two points of departure: Functional and semiotic. The main difference in the definition of organizational culture is that it can be regarded as an organization's characteristic or as a metaphor that helps explain what organizations actually are. Only in the first case is a culture linked to the organization's performance. This is also the most common definition, which is always 
followed by a distinction between organizational culture and organizational climate. The latter refers to a more temporary ambience within the organization.

This study departs from the principle that culture stems from a sociological origin. Cultures are owned by organizations (Garcés and Morcillo, 2012). A functional approach assumes that cultures emerge from collective behavior. It is also essential that within this paradigm the researchers are able to interpret the culture and that the managers must be able to change it. In other words, there is a relationship between performance and culture (Valmohammadi and Roshanzamir, 2015). Organizational culture is a concept that distinguishes itself from personal and societal culture. An organization can, nevertheless, have multiple subcultures (Schneider et al., 2013).

The organizational culture guarantees both stability and the ability to adapt. It holds the organization together and serves as a breeding ground for adaptations within the organization's mission. As the outside world grows increasingly more turbulent, it is of a greater importance that the organization's culture anticipates on the changing environment. According to Cameron and Quinn (2011), an organization's culture is reflected in the values it cherishes. These values are: The dominant characteristics, leadership styles, the binding agent (language, symbols, procedures and fixed rules), personnel management, strategy and the definitions of success that makes the organization unique.

A discussion of organizational culture cannot occur without paying attention to its 2 types of dimensions: Content and pattern dimensions (Cameron and Quinn, 2011). Content dimensions are the cultural aspects utilized to allow staff to familiarize themselves with the culture. The Organizational Culture Assessment Instrument (OCAI) is a tool that helps determine organizational culture. The OCAI comprises 6 typical content dimensions. The first covers the company's dominant characteristics, the second the management style and the companies work methods, the third includes the characteristics of its personnel management, the fourth the organization's binding agent (how does the organization stick together?), the fifth contains the strategic emphases placed by the company and the sixth the criteria for success that it adheres to. When those involved are being confronted with these dimensions, conclusions can be drawn in respect to the organizational culture.

There also appears to be 3 dominant pattern dimensions, namely the cultural strength (the strength ascribed to the culture when decisions are being made), the cultural congruence (to what extent do the subcultures within the organization correspond to one another) and the type of culture. More than 20 typologies of pattern dimensions are mentioned in the literature, such as power distance, individualism, masculinity, femininity and risk appetite (Hofstede et al., $2005)$. It should not go without mention, however, that the strong culture, the congruent culture and culture type are said to be the most prevalent pattern dimensions. Cameron and Ettington (Cameron and Quinn, 2011) discovered that an organization's effectiveness relates to the existing culture type more than to the congruence or strength of its culture. In a comparative study between excellently performing and weaker performing businesses that are similar, Kotter et al. (1995) found that patterns like strength, type and congruence were equally important.

\section{Determining the Organizational Culture}

It is mostly the OCAI developed by Cameron and Quinn (2011) that is used to determine the organizational culture. The instrument is based on the theoretical model of the Competing Values. The theoretical model is reflected in 4 quadrants. Each quadrant represents a main type of culture (family, adhocracy, hierarchy and market). The family culture is characterized by a very friendly work environment where people have a lot in common; the leaders are regarded as mentors and the organization is held together by loyalty and tradition. Commitment is high. Throughout the organization the emphasis lies on the long-term advantages of human resource development and great value is attached to cohesion and morale. The organization highly values teamwork, participation and consensus.

Characteristics of the adhocracy culture are a dynamic, proactive and creative work environment. These people take risks. The leaders are regarded as innovators and risk-takers. For the long term the organization places the emphasis on growth and tapping into new sources. Success is to have new products or services; being a front runner in this respect is seen as vital. The organization promotes individual initiative and freedom.

The third culture is the hierarchical culture. This type is defined by a very formalized and structured work environment. Procedures determine what people do and maintaining a smooth-running organization is important. The long-term focus is on stability and results, together with an efficient and smooth execution of duties. Success is determined within the framework of reliable delivery, smooth planning and low costs.

Market culture is, according to Cameron and Quinn (2011), the fourth main cultural type. An organization with a market culture focuses on results and revolves around the completion of the work. The people are competitive and goal-oriented. The leaders are drivers, producers and competitors, all in one; they are tough and demanding. Reputation and success are important items. As for the global outlook, all staff focus on 
competitive activities and the attainment of measurable aims and objectives. Achievements are defined within the framework of market share and market penetration. Competitive pricing and market leadership are essential. The organizational style is typified by unscrupulous competition.

A current and desired culture are determined for each quadrant. If there is a significant measurement difference between the two, this may indicate a lack of common direction and/or an unclear culture. However, it is also possible that the complexity of the environment of different parts of the organization demand that emphasis be placed on specific cultural aspects. In that case, a conscious organizational choice is made-which leaves no room for intervention.

\section{Culture and Customer Value Strategy}

An organization's focus is often reflected in the customer value strategy it has outlined. Treacy and Wiersema (1995) defined 3 strategies: Operational Excellence, Customer Intimacy and Product Leadership. An organization with Operational Excellence as its most highly valued principle will market reliable products and service for as low a price as possible so that it can compete. Customer Intimacy, on the other hand, makes the organization focus on the client's demands and good service. The products are tailor-made, which makes it crucial to know what the customer wants with an overall focus on the market. The third strategy is Product Leadership. This means that the products are innovative (Treacy and Wiersema,
1995). It is important to have a strategy that complements the product but also matches the characteristics of the organization, such as its culture. If the culture and strategy do not correlate, there is the risk that initiatives are set up which do not fit the strategy. This would result in a waste of energy and resources (Treacy and Wiersema, 1995). If, on the other hand, the organization's objectives are in line with its culture, then the culture is a strong resource for the organization's performance (Osarenkhoe, 2008).

Each client value strategy affects the organization's structure and culture (QA, 2016). Product Leadership entails a loose adhocracy culture that provides opportunities to continually adapt; there is room for experimentation and management focuses on results. The business culture stimulates excellence and imagination whilst encouraging ideas. Product Leadership thereby coincides with both the market and adhocracy cultures. With Operational Excellence, the product's lead time has been optimized and management is focused on quick transactions. The business culture is such, that efficiency is rewarded and waste is abhorred. Operational Excellence ties in with Cameron and Quinn's hierarchical culture. With Customer Intimacy the emphasis is on the core processes and the people closest to the customer have decisive authority. The management concentrates on a well-selected and highly cared for client list and the business culture is geared to customer-specific work and long-term relationships (Fig. 1).

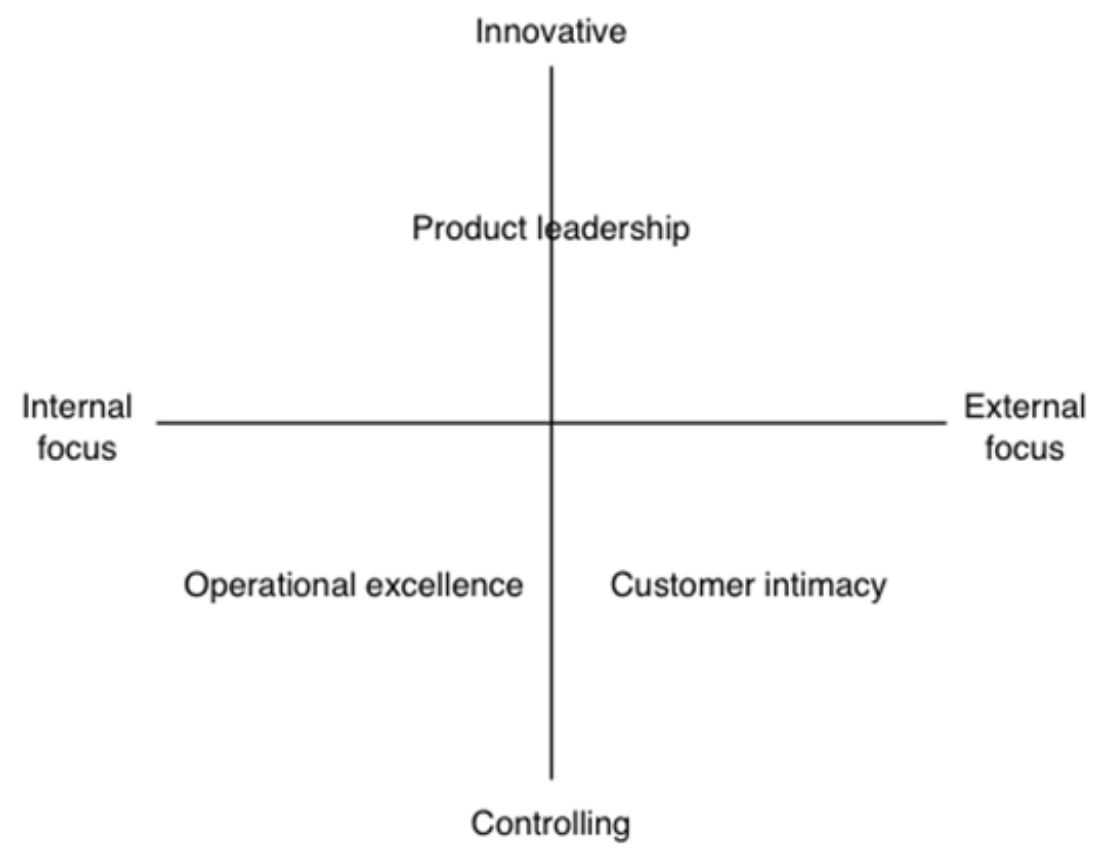

Fig. 1. The relationship between value-disciplines and organizational culture 


\section{Methodology}

In this study the organizational culture of a team within a housing association was compared with the association's organizational culture according to its external stakeholders. The comparison between the scores of the current culture from the two perspectives (IST employees, IST stakeholders) could reflect a discrepancy between the team and the stakeholders. A difference between the current culture from the perspective of the staff (IST employees) and the desired culture from the outlook of the external stakeholders (SOLL stakeholders) would reveal a need for the greatest possible change (transition). Customer value strategies can also be scrutinised against Cameron and Quinn (2011) model. Operational Excellence coincides with the hierarchical culture in this model. Customer Intimacy corresponds to a market culture and Product Leadership to adhocracy. In this study the OCAI scores were also compared with the customer value strategies the organization opted for.

The organizational culture was measured with the OCAI. The OCAI comprises 6 dimensions, whose scores can be attributed to the 4 culture quadrants. The dimensions are: dominance characteristics, management, personnel management, the binding agent, strategy and success. Each respondent answered 12 questions, each with 4 sub-questions in the form of descriptions over which the respondent had to divide 100 points. For each culture quadrant an IST score (current culture) and a SOLL score (desired culture) was calculated on the basis of the answers. These scores were then compared. The OCAI is a validated and reliable instrument with a Cronbach alpha varying from 0.71 to 0.79 (Cameron and Freeman, 1991; Quinn and Spreitzer, 1991; Yeung et al., 1991).

\section{Respondents}

The members of an account team within the housing association were asked to fill in the OCAI. This team is responsible for the customer relations management in the area and is in charge of the organization's service provision. A total of $22(100 \%)$ team members completed the questionnaire.

A divers group of external stakeholders were also asked to fill in the questionnaire. These stakeholders all had dealings with the organization in some way and could therefore form an adequate idea of its culture. They also represent the different types of stakeholders of this housing association, from government agencies to the end-users of the housing, namely the tenants. The OCAI was answered by $61 \quad(70.87 \%)$ external stakeholders, such as tenants, municipal officers, community police officers and contractors. Table 1 presents an overview of the external stakeholders who participated in this study.
Table 1. Characteristics of the stakeholder respondents

\begin{tabular}{ll}
\hline$N$ & Type of stakeholder \\
\hline 11 & Municipal officers (alderman, project leaders, etc.) \\
4 & Contracting firms \\
5 & Police \\
20 & Tenants' Association and tenants \\
26 & Others (legal specialist, estate agent, bank employees, etc.) \\
\hline
\end{tabular}

\section{Results}

The team and stakeholder scores on the OCAI are shown in Fig. 2. These stakeholders' current (IST) and desired (SOLL) scores barely differ from the team's IST and SOLL scores. The image that the team projects to the outside world therefore corresponds to the way it perceives itself. The external stakeholders' scores reveal that the family culture can remain at the same level and a small degree of consolidation in that quadrant in the future would be appreciated. According to the stakeholders the adhocracy culture may be more strongly developed. The hierarchical and the market culture could be reduced further in the future according to both the employees and the stakeholders and the market culture is only ascribed a very limited importance.

Overall, the scores on family and adhocracy are considerable higher than the scores on market and hierarchy culture types. It can thus be concluded that the organization has a strong homogeneous culture with the emphasis on family and adhocracy. From the family perspective, loyalty and tradition are important within the organization as well as teamwork and consensus. From the adhocracy perspective, the organizational culture can be described as proactive, creative and risk taking (Cameron and Quinn, 2011). This can be an advantage in a stable market. However, the context of the outside world where housing associations perform their activities is highly subject to changes; a homogeneous culture can then be an obstacle if the organization is required to adapt accordingly.

From the literature it could be stated that for an organization to perform well, the culture types should correspond with certain customer value strategies (Osarenkhoe, 2008). In this case study the team and stakeholders scored lowest on the market culture quadrant and thereby the Customer Intimacy value strategy should not be the focus of this organization. The team also scored low on the hierarchy quadrant and subsequently so on the Operational Excellence customer value strategy. The team recorded high on the family quadrant and high on the adhocracy quadrant and, as such, the Product Leadership customer value strategy is the favorite. According to the scores on the culture types, the organization should have a focus on Product Leadership. 


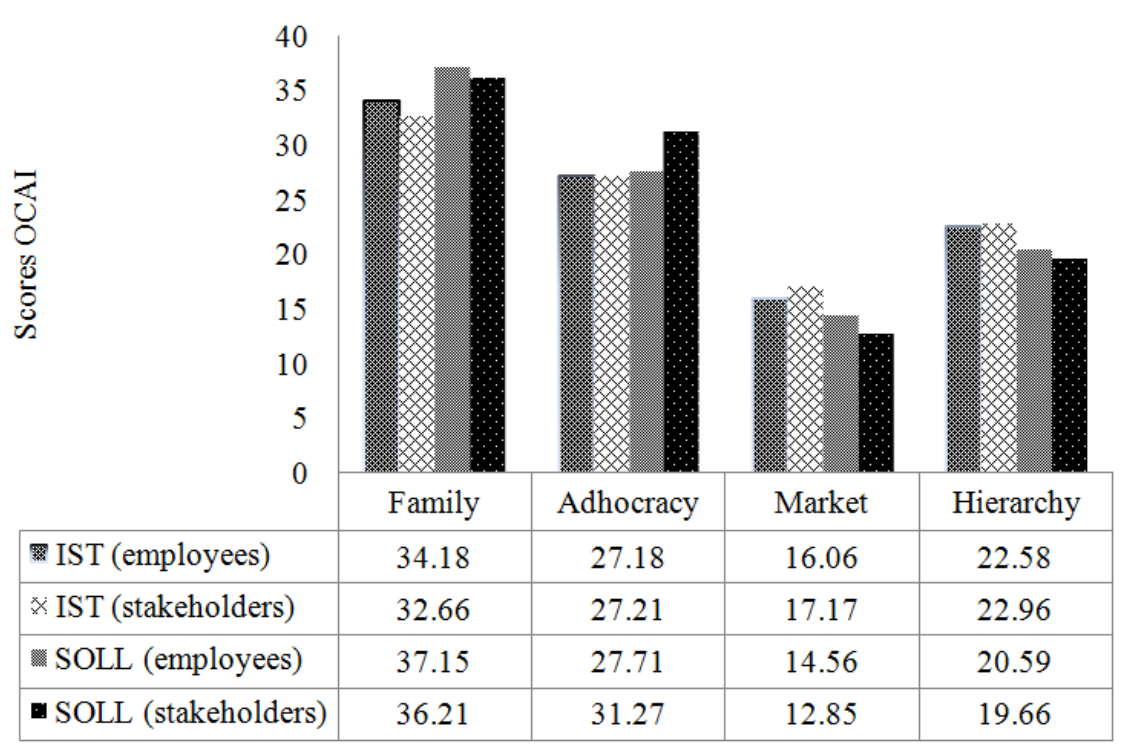

Fig. 2. Team and stakeholder scores on the various culture quadrants

These results however do not correspond to the customer value strategy of Customer Intimacy with attention to Operational Excellence as defined in the organizational goals by the housing association of this case study (Treacy and Wiersema, 1995).

\section{Conclusion and Recommendations}

The organization has chosen Customer Intimacy as its most important customer value strategy with attention to Operational Excellence. This study found that this strategy does not correspond to the organizational culture according to the staff nor from the external stakeholders' perspective. A reorientation on the customer value strategy is therefore recommended. Another possibility is to make the presentation of the Customer Intimacy customer value strategy more recognizable to the external world. If the organization holds on to its current customer value strategy, the communication should be more perceptibly connected with its legitimacy for existence. The various communications at all levels within the organization and to the outside world should also correspond. This could help steer not only the customers' and partners' expectations, but also the staff's performance obligations. Communication should have more of a bridging role, both internally and externally. The organization should keep up its service provision in a distinctive way and put it to even better practice. The most powerful form of communication is behavior-or leading by example. This organization serves its clients and its partners with behavior. It also binds its staff by offering them a wide range of duties with substantial authorities.

This case study can serve as an example to organizations dealing with similar problems. It also demonstrates that the OCAI can be used to determine not only the organizational culture from the organization's perspective, but also from the perspective of the outside world. This allows for an examination as to whether the organization's image corresponds to the organization's own perception or desired image.

\section{Acknowledgement}

The authors would like to thank the Research Centre of Employability for supporting this research.

\section{Author's Contributions}

Ronald Jungnitsch: Development of the conceptual framework, data collection, analysis and drafting the article.

Jol Stoffers: Contributed to analyses and interpretation of the results, preparation of the final version of the article, reviewing the article critically.

Petra Neessen: Contributed to analyses and interpretation of the results, preparation of the final version of the article.

\section{Ethics}

No conflict of interest during the research, the writing of this article and its publication.

\section{References}

Aarons, G.A., L.R. Farahnak, M.G. Ehrhart and M. Sklar, 2014. Aligning leadership across systems and organizations to develop a strategic climate for evidence-based practice implementation. Ann. Rev. Public Health, 35: 255-274.

DOI: 10.1146/annurev-publhealth-032013-182447 
Aslander, M. and E. Witteveen, 2015. Nooit af [Never completed]. Business Contact, Amsterdam.

Cadden, T., D. Marshall and G. Coa, 2013. Opposites attract: Organisational culture and supply chain performance. Supply Chain Manage. Int. J., 18: 86-103. DOI: $10.1108 / 13598541311293203$

Cameron, K.S. and S.J. Freeman, 1991. Cultural congruence, strength and type: Relationships to effectiveness. Res. Organ. Change Develop., 5: 23-58.

Cameron, K.S. and R.E. Quinn, 2011. Diagnosing and Changing Organizational Culture: Based on the Competing Values Framework. 3rd Edn., John Wiley and Sons Ltd, New York, ISBN-10: 1118003322, pp: 288.

Dreimuller, A.P., 2008. Veranderen is voor anderen: Een onderzoek naar verandermanagement bij woningcorporaties [Research on changemanagement at housing associations]. Erasmus University, Rotterdam.

Garcés, M.I. and P. Morcillo, 2012. The role of organisational culture in the resource-based view: An empirical study of the Spanish nuclear industry. Int. J. Strategic Change Manage., 4: 356-378. DOI: 10.1504/IJSCM.2012.051864

Hofstede, G., G.J. Hofstede and M. Minkov, 2005. Cultures and Organizations: Software of the Mind. 3rd Edn., McGraw Hill Professional, New York, ISBN-10: 0071770151, pp: 576.

Kotter, J.P., J.L. Heskett and T.H.J. Tromp, 1995. Organizational culture and performance. Scriptum Books, Schiedam.

Lines, B.C., K.T. Sullivan, J.B. Smithwick and J. Mischung, 2015. Overcoming resistance to change in engineering and construction: Change management factors for owner organizations. Int. J. Project Manage., 33: 1170-1179.

DOI: 10.1016/j.ijproman.2015.01.008
Osarenkhoe, A., 2008. What characterises the culture of a market-oriented organisation applying a customerintimacy philosophy? Database Market. Customer Strategy Manage., 15: 169-190. DOI: $10.1057 / \mathrm{dbm} .2008 .14$

Quinn, R. and G. Spreitzer, 1991. The Psychometric of the Competing Values Culture Instrument and an Analysis of the Impact of Organizational Culture on Quality of Life. In: Research in Organizational Change and Development: An Annual Series Featuring Advances in Theory, Woodman, R.W. and W.A. Pasmore (Eds.), JAI Press, Greenwich, ISBN-10: 1559382503, pp: 322-322.

Schneider, B., M.G. Ehrhard and M.H. Macey, 2013. Organizational climate and culture. Ann. Rev. Psychol., 64: 361-388.

DOI: 10.1146/annurev-psych-113011-143809

Treacy, M. and F. Wiersema, 1997. The Discipline of Market Leaders: Choose your Customers, Narrow your Focus, Dominate your Market. 1st Edn., Basic Books, New York, ISBN-10: 0201407191, pp: 210.

Valmohammadi, C. and S. Roshanzamir, 2015. The guidelines of improvement: Relations among organizational culture, TQM and performance. Int. J. Product. Econom., 164: 167-178. DOI: 10.1016/j.ijpe.2014.12.028

Yeung, A., J. Brockbank and D. Ulrich, 1991. Organizational Culture and Human Resources Practices: An Empirical Assessment. In: Research in Organizational Change and Development: An Annual Series Featuring Advances in Theory, Woodman, R.W. and W.A. Pasmore (Eds.), JAI Press, Greenwich, ISBN-10: 1559382503, pp: 322-322.

QA, 2016. Klantgerichtheid-Treacy and Wiersema. Quinn Association. 